\title{
The Papilla of Vater just below the Pylorus Presenting as Recurrent Duodenal Ulcer Bleeding
}

\author{
Hye Young Sung, Jin Il Kim, Yong Bum Park, Dae Young Cheung, Se Hyun Cho, \\ Soo-Heon Park, Joon-Yeol Han and Jae Kwang Kim
}

\begin{abstract}
The papilla of Vater emptying into the duodenal bulb site is extremely rare and considered an aberrant condition. We report here a case with recurrent duodenal ulcer bleeding associated with this anomaly. A 42year-old man was admitted to St. Mary Hospital because of tarry stool for three days. Despite no documented etiology to explain recurrent ulceration, the patient had about ten episodes of ulcer bleeding since 1995. On duodenoscopy, $1.0 \times 0.6 \mathrm{~cm}$ sized active stage duodenal ulcer with oozing was observed at the posterior wall side below the pylorus. The papilla of Vater was bulging just below the pylorus. Bile juice was excreted from its opening. Pancreatic duct and common bile duct, which drained into the bulb site, were observed on ERCP. In this report, we show that recurrent duodenal ulcer can be associated with the papilla of Vater just below the pylorus.
\end{abstract}

Key words: papilla of Vater, ERCP, duodenal ulcer

(DOI: 10.2169/internalmedicine.46.0190)

\section{Introduction}

The papilla of Vater typically enters the posteromedial aspect of the second portion of the duodenum through an oblique, $1 \mathrm{~cm}$ to $2 \mathrm{~cm}$, long intramural tunnel. At times, it can terminate at aberrant sites, including the stomach (1-3), pyloric canal, duodenal bulb (4-9), and the third or fourth portion of the duodenum (10-12). Most commonly, the distance between the pyloric sphincter and the papilla of Vater is longer than $5 \mathrm{~cm}$. Such a distance can be reduced by an aberrant opening of the papilla of Vater into the bulb; in this situation, secreted bile and pancreatic juice can not only irritate the duodenal bulb but also the gastric mucosa by reflux mechanisms. These abnormal refluxes can lead to various clinical symptoms such as chronic epigastric pain or recurrent ulcer bleeding. Clinically, a papilla of Vater adjacent to the pylorus and its associated symptoms can provoke chronic recurrent or intractable duodenal ulcer disease (5). We present here a patient with recurrent duodenal ulcer bleeding caused by papilla of Vater just below the pylorus.

\section{Case Report}

A 42-year-old man was transferred to St. Mary's Hospital for further evaluation of recurrent upper gastrointestinal bleeding. He complained of tarry stool for three days. He had had chronic epigastric pain that was described to occur 2 hours after eating. The patient had experienced about ten episodes of upper gastrointestinal bleeding over the past 10 years. At his primary care clinic he had been diagnosed with recurrent duodenal ulcer and maintained on proton pump inhibitor as antiulcer medication throughout the year due to postprandial epigastric pain and chronic dyspepsia. He received Helicobacter pylori eradication treatment seven years prior to presentation. He had no past history of NSAID medication or smoking.

On admission, the physical examination was unremarkable. Respiratory rate was $22 / \mathrm{min}$, blood pressure $130 / 80$ $\mathrm{mmHg}$, pulse rate $80 / \mathrm{min}$ and temperature $36.8^{\circ} \mathrm{C}$. Hematologic examination showed within normal limit; hemoglobin $15.3 \mathrm{~g} / \mathrm{dl}$ and hematocrit $44.2 \%$. Routine biochemistry was unremarkable; AST 28 IU/l, ALT 22 IU/l, gamma glutamyl transpeptidase $19 \mathrm{IU} / \mathrm{l}$, alkaline phosphatase $228 \mathrm{IU} / \mathrm{l}$, 


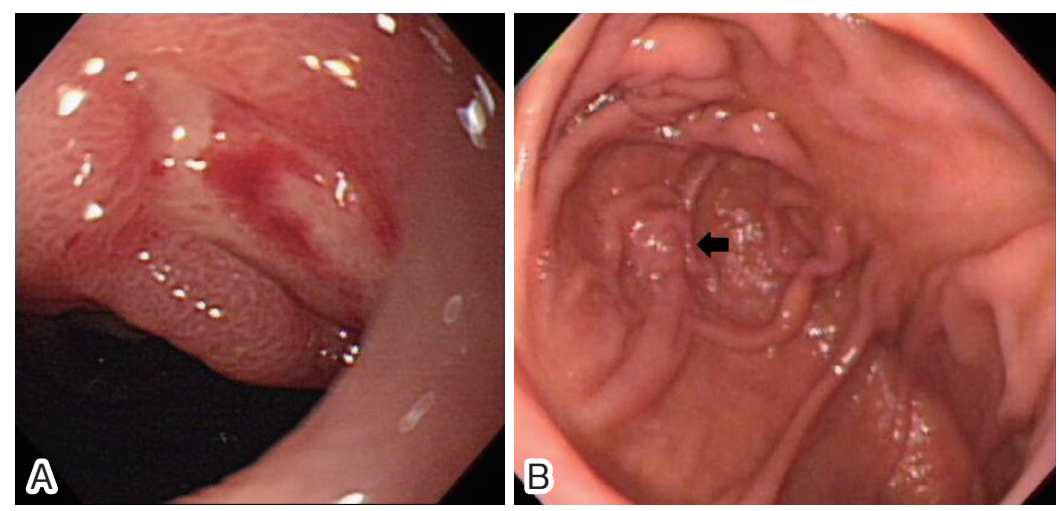

Figure 1. Endoscopic image. A: An active stage duodenal ulcer $(1.0 \times 0.6 \mathrm{~cm})$ with oozing was seen. B: Papilla of Vater was located just below the pylorus.

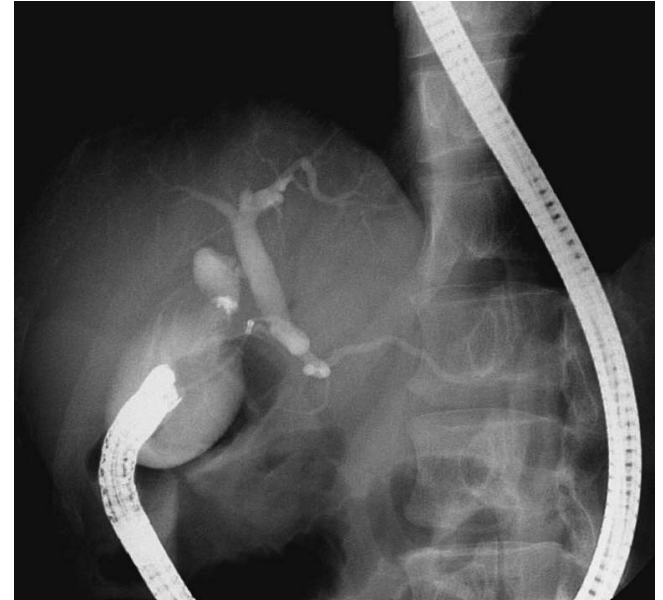

Figure 2. ERCP image. Contrast dye was injected through the papilla of Vater opening in the duodenal bulb. Then the main pancreatic duct and the common bile duct were enhanced.

and total bilirubin $0.79 \mathrm{mg} / \mathrm{dl}$. Endoscopy revealed $1.0 \times 0.6$ $\mathrm{cm}$ sized active stage duodenal ulcer with oozing at the posterior wall below the pylorus (Fig. 1A). There was no duodenal bulb, which was replaced by the second portion and it was noted that the papilla-like structure was bulging into the duodenal bulb site (Fig. 1B), and the appearance of that was non-specific. No other papilla-like structure existed in the second or third duodenal portion. Bile juice was excreted intermittently from its opening site, especially when suction was applied with the endoscope. ERCP was performed. We cannulated and injected contrast medium via the orifice which was observed previously at the duodenal bulb site. We observed that the main pancreatic duct drained into the papilla of Vater at the duodenal bulb site without a connection to the accessory pancreatic duct. The common bile duct (CBD) was connected to distal portion of main pancreatic duct (Fig. 2). In short, we clearly demonstrated that CBD and pancreatic main duct formed a common channel; this common channel drained into the papilla of Vater just below the pylorus. CLO test for Helicobacter pylori and WarthinStarry silver stain in biopsy were negative.
Since the last episode of duodenal ulcer bleeding, the patient was maintained on a proton pump inhibitor, rabeprazole $10 \mathrm{mg}$ /day. Using a 24 hour gastric $\mathrm{pH}$ monitoring, we found a well suppressed acid condition with an abnormally elevated $\mathrm{pH}$ (more than $\mathrm{pH}$ 6) present all of the time (Fig. 3). On the notion that the recurrent duodenal ulcer bleeding can be caused not only by the gastric acid but also by the bile and pancreatic secretions, treatment was targeted on the proton pump, rabeprazole $20 \mathrm{mg} / \mathrm{day}$, and the pancreatic enzyme, camostat mesilate (Foipan ${ }^{\circledR}$ ) $300 \mathrm{mg} / \mathrm{day}$, accordingly. The patient had no further bleeding episodes and remained hemodynamically stable for the remainder of the hospital day. On the 7th day after admission, the patient was discharged from the hospital. Rabeprazole was prescribed for an additional 8 weeks: camostat mesilate treatment was planned for one additional year. The patient has been doing well and denied any gastrointestinal symptoms. Follow-up esophagogastroduodenoscopy after one year demonstrated that the gastric mucosa was normal, the previous ulcerated duodenum was healed; however, the bulb site and duodenal second portion deformity remained; the papilla of Vater was bulging in the bulb without change.

\section{Discussion}

The papilla of Vater is a nipple-like elevation of the duodenal mucosa at the site of termination of the common bile duct and pancreatic duct. The papilla of Vater typically enters the posteromedial aspect of the second portion of the duodenum through an oblique, $1 \mathrm{~cm}$ to $2 \mathrm{~cm}$ long, intramural tunnel. The CBD runs obliquely downward within the wall of the duodenum for 1 to $2 \mathrm{~cm}$ before opening onto a papilla of mucosal membrane, called the papilla of Vater, about $10 \mathrm{~cm}$ distal to the pylorus. Then the CBD forms a common union with the main pancreatic duct in most cases. At times, they can terminate at anomalous sites, including the stomach (1-3), the pyloric canal, duodenal bulb (4-9), and the third or fourth portion of the duodenum (10-12). Generally, it terminates in the third or fourth portion of the duodenum (10-12). Cases of an anomalous opening in the bulb including autopsy cases have been reported in six lit- 


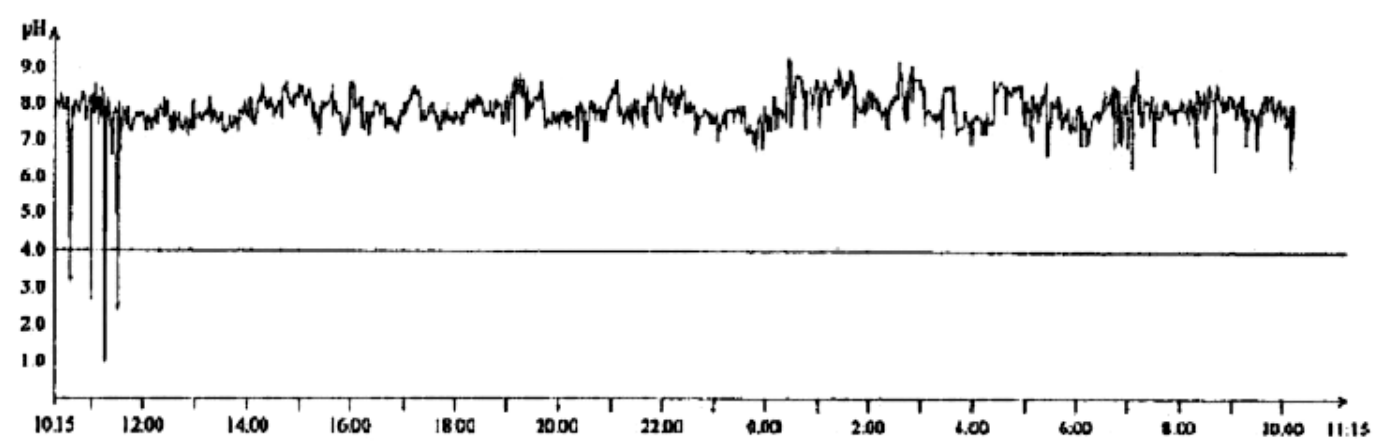

Figure 3. Continuously elevated pH was revealed by 24 hour gastric pH monitoring. This condition is thought to effect of bile reflux.

eratures (4-9). Recently, Disibeyaz et al reported that in $0.44 \%$ of 12,158 patients subjected to ERCP, the papilla of Vater was opening in the duodenal bulb (9). In the vast majority of which the distance between the papilla of Vater and the pyloric sphincter was reported to be usually less than 5 cm (4-9): it is very rare to be less than $1.5 \mathrm{~cm}$, as in the present case.

Aberrant opening of papilla of Vater in the bulb is not an incidental finding, but a pathologic condition which can be associated with clinical entities such as recurrent or intractable duodenal ulcer, recurrent biliary pain, choledocholithiasis or acute cholangitis $(5,10,11)$. A missing duodenal bulb and strictures of the secondary duodenal portion including the papilla of Vater following the pylorus defines this case report. The process which occurred in this anomaly can only be conjectured. It may be a congenital anomaly or a result of recurrent duodenal ulcer shortening the bulb and dislocating the secondary portion. In this anomaly, significant duodeno-biliary reflux and stasis can occur due to loss of the oblique course of the common bile duct and the pancreatic duct in the duodenal wall. Not only the gastric juice but also the pancreatic juice and bile juice may contribute to the recurrent peptic ulcer. So called "alkaline reflux" may be a cause of mucosal injury resulting in peptic ulcer. Such a clinical feature can be easily seen upon gastric surgery, cholecystectomy, ampullary sphincteroplasty, and, rarely, in nonoperated patients (13-15). It is well documented that duodeno-biliary reflux can cause injury to gastric and esophageal mucosa; chronic irritation may cause gastritis, esophagitis, gastric ulcer and even esophageal carcinoma (16-18). An animal study has shown that esophageal mu- cosal injury can be caused by external influx of bile and pancreatic secretions (19). In addition, another study suggested synergistic damaging potential for conjugated bile acids and hydrochloric acid as well as that of unconjugated bile acids and trypsin at more neutral $\mathrm{pH}$ values (18). Bile is very ionic and can lead to mucosal damage by deteriorating the surfactant characteristics of the protective mucous layer (20). Therefore, deformation of the duodenal bulb can develop after chronic exposure to the noxious effects of ionic bile acids and alkaline $\mathrm{pH}$ causing mucosal damage and ulceration, which cannot be prevented by cytoprotective mechanisms (21).

In the cases that present with recurrent ulcer bleeding caused by papilla of Vater in the bulb, there are no established treatment guidelines. The major ulcerogenic irritants of the present case might have been the bile and pancreatic secretion caused by this anomaly. Therefore, we added camostat mesilate to the antiulcer medication, rabeprazole. At the over one year follow-up after admission, the patient was doing well and without symptoms.

The patient had been maintained on anti-ulcer medication throughout the year due to postprandial epigastric pain and chronic dyspepsia. However, he had experienced several episodes of a bleeding ulcer. Therefore, we added camostat mesilate and observed that it had a major role in preventing ulcer and improving symptoms. In this report, we clearly demonstrate that recurrent duodenal ulcer can be caused by bile and pancreatic secretions which are drained from papilla of Vater in the duodenal bulb, and can be treated successfully by adding camostat mesilate to anti-ulcer medications.

\section{References}

1. Kanematsu M, Imaeda T, Seki M, Goto H, Doi H, Shimokawa K. Accessory bile duct draining into the stomach: case report and review. Gastrointest Radiol 17: 27-30, 1992.

2. Pereira-Lima J, Pereira-Lima LM, Nestrowski M, Cuervo C. Anomalous location of the papilla of Vater. Am J Surg 128: 7174, 1974.

3. Moosman DA. The surgical significance of six anomalies of the biliary duct system. Surg Gynecol Obstet 131: 655-660, 1970.

4. Kubota T, Fujioka T, Honda S, et al. The papilla of Vater empty- ing into the duodenal bulb. Report of two cases. Jpn J Med 27: 79-82, 1988.

5. Lee SS, Kim MH, Lee SK, et al. Ectopic opening of the common bile duct in the duodenal bulb: clinical implications. Gastrointest Endosc 57: 679-682, 2003.

6. Rosario MT, Neves CP, Ferreira AF, Luis AS. Ectopic papilla of Vater. Gastrointest Endosc 36: 606-607, 1990.

7. Keddie NC, Taylor AW, Sykes PA. The termination of the common bile duct. Br J Surg 61: 623-625, 1974. 
8. Krstic M, Stimec B, Krstic R, Ugljesic M, Knezevic S, Jovanovic I. EUS diagnosis of ectopic opening of the common bile duct in the duodenal bulb: a case report. World J Gastroenterol 11: 50685071,2005

9. Disibeyaz S, Parlak E, Cicek B, et al. Anomalous opening of the common bile duct into the duodenal bulb: endoscopic treatment. BMC Gastroenterol 7: 26-26, 2007.

10. Lindner HH, Pena VA, Ruggeri RA. A clinical and anatomical study of anomalous terminations of the common bile duct into the duodenum. Ann Surg 184: 626-632, 1976.

11. Quintana EV, Labat R. Ectopic drainage of the common bile duct Ann Surg 180: 119-123, 1974.

12. Doty J, Hassall E, Fonkalsrud EW. Anomalous drainage of the common bile duct into the fourth portion of the duodenum. Clinical sequelae. Arch Surg 120: 1077-1079, 1985.

13. Bondurant FJ, Maull KI, Nelson HS, Silver SH. Bile reflux gastritis. South Med J 80: 161-165, 1987.

14. De Rose G, Duff JH. Bile reflux gastritis and esophagitis. Can J Surg 23: 190-191, 194, 1980.
15. Nath BJ, Warshaw AL. Alkaline reflux gastritis and esophagitis. Annu Rev Med 35: 383-396, 1984.

16. Fein M, Peters JH, Chandrasoma P, et al. Duodenoesophageal reflux induces esophageal adenocarcinoma without exogenous carcinogen. J Gastrointest Surg 2: 260-268, 1998.

17. Attwood SE, Smyrk TC, DeMeester TR, Mirvish SS, Stein HJ, Hinder RA. Duodenoesophageal reflux and the development of esophageal adenocarcinoma in rats. Surgery 111: 503-510, 1992.

18. Vaezi MF, Singh S, Richter JE. Role of acid and duodenogastric reflux in esophageal mucosal injury: a review of animal and human studies. Gastroenterology 108: 1897-1907, 1995.

19. Cross FS, Wangensteen $\mathrm{OH}$. Role of bile and pancreatic juice in production of esophageal erosions and anemia. Proc Soc Exp Biol Med 77: 862-866, 1951.

20. Northfield TC, Mc Coll I. Postprandial concentrations of free and conjugated bile acids down the length of the normal human small intestine. Gut 14: 513-518, 1973.

21. Brown TH, Walton $\mathrm{G}$, Cheadle WG. The alkaline shift in gastric pH after cholecystectomy. Am J Surg 157: 58-65, 1989.

(C) 2007 The Japanese Society of Internal Medicine http://www.naika.or.jp/imindex.html 